\title{
DOSSIÊ
}

\section{Uma experiência de integração das Polícias Civil e Militar: os Distritos- Modelo em Fortaleza}

GLAUCÍRIA MOTA BRASIL*E DOMINGOS ABREU**

\section{Introdução}

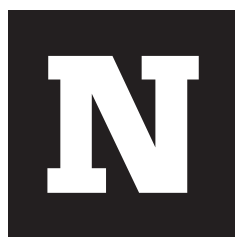

osso objetivo no presente artigo é colocar em discussão alguns aspectos observados no cotidiano de integração dos policiais civis (PCs) e militares (PMs), durante a realização de uma pesquisa de campo ${ }^{1}$, na área de um Distrito-Modelo (DM) na cidade de Fortaleza.

O eixo de nossa reflexão inicial tem como ponto de partida a mudança na sistemática de trabalho dos aparelhos policiais, com a instalação do DM, que tem como principal exigência a integração das atividades das polícias militar e civil, ou seja: como essa mudança vai alterar a ação policial na estrutura de funcionamento dos aparelhos policiais? A partir desta perspectiva, acreditamos que um deslocamento do estudo da polícia para o estudo do policial seja mais instigante e esclarecedor, considerando ser este o eixo de estruturação dos significados que formam a ação policial,

$\overline{{ }^{*} \text { Assistente social, doutora em Políticas Sociais pela PUCSP, }}$ professora da UECE, coordenadora do LABVIDA-UECE e pesquisadora associada do LEV-UFC.

** Sociólogo, doutor em Sociologia pala UFC, professor da UFC e pesquisador do LEV-UFC.

1 Este trabalho faz parte da pesquisa Segurança Pública no "Governo das Mudanças": participação comunitária e influência externa no Estado do Ceará, financiada pela Fundação FORD e realizada pelo Laboratório de Estudos da Violência da Universidade Federal do Ceará- LEV-UFC, sob a coordenação do prof. dr. César Barreira e pelos pesquisadores profa. dra. Rosemary de Oliveira Almeida, prof. dr. Domingos Abreu e profa. dra. Glaucíria Mota Brasil. 
em grande parte independendo de estruturas organizacionais, tantas vezes reformadas sem alcançar resultados efetivos (Bretas, 1997, p. 81).

Faz-se necessário, antes, compreender o que representa o projeto Distrito Modelo (DM) na política de segurança pública do Ceará. O DM nasceu da proposta de racionalidade e integração das atividades policiais da consultoria externa contratada pelo segundo governo Tasso Jereissati (1995-1998) à empresa norte-americana First Security Consulting, dirigida por William Bratton, ex-chefe da polícia de Nova York, responsável pela implantação da chamada política de "tolerância zero" ${ }^{2}$ da polícia novaiorquina no enfrentamento das "altas taxas" de criminalidade e violência naquela metrópole, no período de 1994-96. Com a implantação do projeto DM, as atividades policiais passaram a ser desenvolvidas integradamente, ou seja, um DM compreende a integração das atividades policiais de uma Companhia da PM, delegacias de polícia e Grupamento de Incêndio do Corpo de Bombeiro Militar - CBM -, numa mesma área geográfica e entre as áreas dos DMs (Brasil, 2000).

O núcleo central do DM é a reformulação da sistemática do trabalho policial através da unificação das ações desenvolvidas pela PM, PC e CBM, com o objetivo de racionalizar e estreitar a colaboração e o apoio entre as duas polícias no combate à criminalidade. $\mathrm{O}$ instrumental de trabalho responsável por esta integração se chama Relatório de Crime ou ficha de coleta de dados (cronologia e autoria dos delitos e crimes praticados em determinadas áreas da cidade), e passou a ser usado pelos policiais militares e civis para registrar todas as ocorrências notificadas e, em seguida, estas são

\footnotetext{
2 Mister William Bratton ganhou reputação como chefe de Polícia de New York por ter conseguido baixar as altas taxas de criminalidade da referida metrópole com o emprego de uma estratégia denominada de "tolerância zero", ou seja, punir os autores dos pequenos delitos. A idéia é que quem picha paredes ou pula a catraca do metrô se envolve com mais facilidade em crimes mais graves (Veja, 30/02/02, p. 82). É, ainda, uma política de retirada dos suspeitos de ruas, parques e logradouros públicos, um modo de fazer polícia que vem sendo denunciado por entidades de direitos humanos (como a ONG Human Rigths Watch-Americas) de preconceituoso e discriminador porque visa principalmente às populações pobres, negras e aos imigrantes latinos que estão nas ruas, além de fazer uso da violência e do arbítrio policial (ver Police State, vídeo produzido pelos alunos do Curso de Comunicação da PUCSP sobre as ações da polícia na cidade de New York) (Brasil, 2000, p. 205). Por outro lado, essa política de tolerância zero, também, se estende ao corpo policial, ao defender o argumento de que esta deve ser bem formada, bem equipada, ter a comunidade como parceira, e qualquer deslize ou corrupção não pode ser tolerado (Veja, 30/02/02, p. 82).
} 
registradas numa central de dados estatísticos das companhias da PM e das delegacias pólos dos DMs. O Relatório de Crimeé, portanto, o instrumental inovador e unificador na metodologia de trabalho das duas polícias. O projeto DM prevê ainda a melhoria das instalações físicas, a aquisição de equipamentos, o aumento do efetivo policial - uma vez que o número de policiais por DM passa em média de 6 para 23 policiais - a compra de viaturas, de sistemas modernos de comunicação e informatização, de armamento e instrumental de segurança e apoio ao serviço policial. Está prevista a instalação de 9DMs na cidade de Fortaleza e mais 3DMs em sua Região Metropolitana (a implantação ainda é parcial) e um projeto para que os DMs sejam implantados em todo o Estado (Brasil, 2000).

A implantação do projeto DM foi iniciada em 1998, com a instalação do DM1, numa área de jurisdição da $4^{a}$ Cia do $6^{\circ}$ BPM, onde estão localizados o $12^{\circ}$ DP (Conjunto Ceará) e o $32^{\circ}$ DP (Bom Jardim), compreendendo 13 bairros e 7 favelas, com uma população estimada em $270 \mathrm{mil} / \mathrm{hab}$. A escolha da referida área para instalar o projeto-piloto do DM levou em consideração, segundo o ex-coordenador do Projeto Distrito Modelo e exsecretário de segurança pública, general João Crisóstomo de Souza, os seus altos índices de homicídios, assaltos e roubos, e as enormes carências sociais e por ter essa área sido considerada uma das mais difíceis (Brasil, 2000, p. 233). Em 1998, a área do DM1 ocupava a quinta colocação em números de homicídios em Fortaleza, uma estatística de 60 homicídios por ano (Jornal O POVO, 22/04/1998, p. 15A). De acordo com dados estatísticos do DM1, em 6 meses de sua implantação, as ocorrências policiais foram reduzidas em 34,5\% (Brasil, 2000, p. 233).

Neste contexto, há que se destacar dois aspectos no trabalho "integrado" das polícias civil e militar: o primeiro diz respeito à própria filosofia da "integração" das polícias com a criação dos DMs; o segundo aspecto trata de um efeito "colateral" dessa integração, ou seja, a presença de PMs no espaço das delegacias de polícia, locus reservado aos PCs que têm a função legal de exercer a polícia judiciária, responsável pela investigação policial. 
A política de "integração" das duas polícias foi uma maneira original encontrada pelo governo cearense para fazer frente à idéia defendida por estudiosos, defensores dos direitos humanos e especialistas em segurança pública: a unificação das polícias estaduais - conceito impossibilitado hoje pela Constituição de 88 que manteve engessada, em seu art. 144, a estrutura dos aparelhos policiais definida pela ditadura militar (Pinheiro, 2001). Frente a essa impossibilidade real, a integração apareceu como a alternativa de racionalização e unificação dos trabalhos policiais.

Na prática, a integração operacionalizada com a instalação dos DMs acabou por misturar policiais civis e militares num mesmo espaço de trabalho e, no caso das delegacias policiais, essa integração se deu de maneira mais intensa em razão do déficit de pessoal da Polícia Civil, ou seja, a implantação dos DMs exigiu um efetivo maior, como pudemos ver anteriormente. No caso da PC, esse déficit, como veremos à frente, é significativamente maior do que na Polícia Militar e, desta maneira, a PC acabou sendo "forçada" a aceitar que PMs "assumissem" o lugar de PCs nas atividades policiais das delegacias distritais. Há outro aspecto dessa integração que diz respeito às atividades e reuniões regulares dos comandos da PC (os delegados), dos bombeiros militares e dos PMs (os oficiais militares), norteadas pelos índices das estatísticas criminais destas áreas no planejamento e operacionalização de estratégias policias de enfrentamento da criminalidade em cada área de suas circunscrições administrativas, assim como as ações comuns que devem ser desenvolvidas pelas PC, PM e pelo CBM nessas áreas.

Dessa maneira, um dos expedientes inusitados dessa integração se dá pelo empréstimo de PMs para as delegacias distritais. Como escrevemos antes, o efetivo da PC no Estado do Ceará convive com um déficit considerável. Se, no início dos anos 80, o número de PCs era de cerca de 3.500, hoje eles são cerca de 2.370 (3.130 hab/policial). A PM tem um efetivo absoluto de 12.215 homens (607 hab/policial). O Ceará possui hoje o segundo menor efetivo policial per capita do Brasil (fonte: Ministério da 
Justiça, 2001). Há, contudo, informações locais de que a Polícia Civil conta hoje com um efetivo de cerca de 1.700 policiais, e a Polícia Militar, em torno de 11 mil homens. A população do Ceará é de 7.430.661 (Fortaleza com 2.138.234 hab. e sua Região Metropolitana com 2.930.374 hab.) (IBGE, 2000).

Caso estivéssemos diante de uma polícia única, os efetivos de hoje nas duas polícias poderiam ser aproveitados de uma maneira mais racional. No entanto, como dito, as polícias têm funções distintas, inconfundíveis e constitucionalmente delimitadas pelo art. 144 da CF. Qual a solução encontrada pelo governo estadual? O empréstimo de PMs para as atividades policiais desenvolvidas nas delegacias de polícia. Dessa forma, PMs foram cedidos para trabalhar sob as ordens dos delegados de polícia, realizando as mais diversas tarefas nas delegacias (atendimento na recepção, registro de boletins de ocorrência, permanência e custódia de presos nos xadrezes, plantão nos finais de semana, entrega de documentos da delegacia e até participação nas investigações policiais - atividades negadas por alguns e confirmada por outros) com o caráter inequívoco de suprir a carência de pessoal civil, ao mesmo tempo que agiliza as muitas atividades desenvolvidas no cotidiano de uma delegacia de polícia e, de certa maneira, desafoga e libera o reduzido efetivo de PCs para o trabalho essencial de polícia investigativa, como nos informam os defensores da medida.

Assim, um dos efeitos da criação dos DMs (um efeito "colateral") foi a inclusão de PMs, de certa maneira, nos serviços de polícia judiciária ou no desenrolar das atividades policiais numa delegacia de polícia. Ora, esta "cooperação" é por demais interessante, sociologicamente falando, haja vista a história das duas corporações (que nunca foi de muita proximidade e mesmo marcada por disputas e rusgas). Poderíamos imaginar que ambas as partes estariam insatisfeitas com esta situação de ambigüidade de funções policiais. No entanto, este é um dos pontos da dinâmica que mais se mostra e que ambas as partes têm tendência a apresentar como um dos "sucessos" do DM, indicando mesmo a parceria ("integração" como é sem- 
pre lembrada por delegados da polícia civil e oficiais da PM) e, noutros momentos, até como uma espécie de prelúdio (distante) para a unificação futura das polícias. Assim, o que perguntamos aqui é: o que mantém funcionando este sistema? O que dá sustentação interna às duas partes para que elas aceitem esta colaboração?

Claro que poderíamos apostar em uma resposta "legalista". Uma leitura deste tipo teria tendência a perceber o Governo do Estado aproveitando a dinâmica do DM para usar indevidamente PMs fazendo as vezes de PCs - escapando, assim, da necessidade de realizar novos concursos públicos para policiais civis, justificado pelo fato de não poder onerar a folha de pagamento do Estado por ter que obedecer a lei de responsabilidade fiscal. Tal afirmação, por sinal, é com freqüência denunciada pelos órgãos representativos da PC (os sindicatos denunciam o governo dizendo que existe uma necessidade de concurso público para PCs e que esta política de PMs "paisanos" prestando serviços nos DMs é escamoteada pela dinâmica da "integração"; que a sociedade estaria sendo enganada pelo governo e que esta situação é ilegal, etc.).

Os defensores da idéia retrucam que não é bem assim, ou seja, não se estaria usando um mero artifício para escalar policiais fora de suas funções, mas, muito mais, integrando as polícias dentro deste novo modelo de fazer segurança pública. Eles lembram também a problemática do grave déficit de pessoal da polícia civil, que deverá ser solucionada com a realização de concurso público para os quadros da Polícia Civil³.

Outra resposta possível está situada no plano da obediência: as polícias não estariam de acordo mas, como o modelo foi imposto, elas obedecem. Este é um elemento certamente importante para que compreendamos parte do comportamento da PM (mais obediente e seguidora da hierarquia e da disciplina). Mais complicado é perceber nesta resposta uma explicação do comportamento da PC (na qual se observa uma "flexibilida-

3 O comando da segurança pública tem prometido à polícia civil a realização de concurso público para 800 cargos (200 escrivães, 100 delegados e 500 inspetores). 
de" da hierarquia e da disciplina). Se formalmente os policias civis aceitam a ordem, informalmente, no cotidiano das delegacias, eles poderiam recusar-se a cumpri-la e mesmo boicotar a presença dos PMs. Lembramos que, em algumas delegacias, as equipes que trabalham com os delegados são quase que integralmente compostas por PMs (um exemplo é o caso da Delegacia de Roubos e Furtos - DRF). De um modo geral, como discutiremos adiante, a presença ou a integração de PMs nas atividades da polícia civil parece ser bem aceita nas delegacias que compõem o DM, tanto pelos delegados como pelos policiais civis e principalmente pelos PMs destacados para essas funções.

Por outro lado, parece-nos bastante plausível que elementos da reflexão dos "legalistas" (uma boa ilustração desta tendência pode ser vista nos sindicatos da polícia civil) possam ser levados em conta na discussão. No entanto, outro elemento que não pode ser esquecido é que os quadros superiores da PM e da PC estão aceitando o que foi imposto pelo comando da SSPDC e, de certa maneira, "pagando para ver" no que vai dar esta experiência de colocar PMs sob a hierarquia e a disciplina dos comandos civis (os delegados de polícia civil). Não só, eles estão observando como se comportam os PMs em contato com os policiais civis e vice-versa (civis que os militares à moda antiga classificam de forma desclassificante como "frouxura"). Seria uma espécie de laboratório, susceptível de trazer elementos de resposta para uma unificação futura das duas polícias e, neste caso, pode-se até dizer que a PM entraria com certa vantagem, uma vez que o seu espaço de ação parece mais amplo ao se inteirar das atividades da polícia judiciária no cotidiano de sua prática, ou melhor, aprendendo a fazer fazendo. Enfim, podemos até levantar a hipótese de que a PM, mais do que a PC, está preparando-se para uma possível mudança de rumo no cenário das políticas de segurança pública e nas suas estruturas de poder no País. Ao nosso ver, uma das vantagens da PM é, sem dúvida, a possibilidade de que seus quadros estão tendo de aprender o ofício da PC nos laboratórios cotidianos das delegacias de polícia, o que facilitaria uma futura unifica- 
ção das duas polícias, considerando, sobretudo, o fato de as propostas de unificação terem mais um caráter civil do que militar na gramática do Estado democrático de Direito.

No entanto o que se propõe mais como pistas do que como respostas nesta parte do trabalho não invalida as especulações anteriores, mas quer dar conta de um aspecto da questão que normalmente fica encoberto por estas preocupações gerenciais macro (seja do ponto de vista dos governantes, seja do prisma das cúpulas das polícias). Dito de outra forma, quer-se dar conta das microrrelações tecidas entre os que são imediatamente implicados pela "integração" dentro das delegacias, ou seja, os PMs e os PCs. Suspeita-se de que ambas as partes têm interesses imediatos nessa "integração" - na realidade, na prestação de serviço dos PMs nas delegacias distritais - e por isso não se opõem ao que está proposto e tampouco fazem alarde negativo da situação como suas entidades representativas.

Neste caso, podemos crer que, se os agentes policiais (militares, mas sobretudo, os civis) não encontrassem nenhum interesse imediato na situação denunciada como "ilegal", que "usurpa" as atividades da polícia judiciária e "força" os PMs a exercerem funções não consideradas como suas atribuições legais, as insubordinações seriam mais visíveis. Ora, não é o que se presencia no cotidiano das delegacias, considerando, acima de tudo, os elementos de interesse que podem ser identificados nas respostas dadas por PMs e PCs, quando indagados sobre a integração de suas atividades num mesmo espaço de ação e acrescidas a outras explicações que venham subsidiar a compreensão desta "dinâmica de sucesso" do DM.

Paralelo a este quadro de integração, outro está sendo desenhado pela inserção e participação de lideranças comunitárias na discussão que subsidia de maneira direta e indireta as ações estratégicas. As lideranças comunitárias, na sua grande maioria, acabaram por se fazer representar nessas discussões, através da chancela dos Conselhos Comunitários de Defesa Social - $\mathrm{CCDS}^{4}$ - que, sob a orientação e coordenação da Diretoria da Cida- 
dania da Secretaria de Segurança Pública e Defesa da Cidadania - SSPDC , reúnem-se com regularidade, na área do DM no qual estão inseridos, com representantes das delegacias distritais e com os comandantes e oficiais das companhias da PM. Nessas reuniões são ouvidas as lideranças. Elas apontam os problemas ocorridos nas suas áreas de inserção, e as polícias traçam planos para resolvê-los. As lideranças são também incentivadas a apontar soluções para problemas específicos, como a falta de policiamento ostensivo, deficiência das rondas noturnas e diárias, solicitação de instalação de cabines da PM em determinados locais de venda de droga, etc. Ainda nessas reuniões, as autoridades policiais prestam contas das ações desenvolvidas para solucionar questões trazidas em reuniões passadas ou em visitas feitas por essas lideranças aos distritos e/ou às companhias da PM. Há, sem dúvida, uma prestação de contas dos serviços policiais às comunidades ou, mais diretamente, às suas lideranças.

\section{Breve história de disputas e rusgas}

Primeiro abordaremos alguns aspectos político-administrativos das polícias civil e militar no Ceará. Em seguida trataremos das disputas travadas entre as duas corporações ao longo de suas histórias. Para que se possam compreender algumas dinâmicas dos DMs, é necessária uma pequena explanação de certos aspectos referentes às duas categorias de polícia no Ceará, antes da Constituição de 1988. Administrativamente o comandante da PM estava subordinado ao secretário de segurança pública. Este, na prática, tinha atribuições de secretário de Estado e despachava diretamente com o governador; ou seja, apesar da existência de uma secretaria de segurança pública (com seus diferentes nomes ao longo dos anos), sob

4 Os Conselhos Comunitários de Defesa Social-CCDS são regulamentados por decreto governamental (Dec. № 25.293, de 11/11/ 1999). Hoje já somam cerca de 700 em todo o Estado. Na prática, esses conselhos têm discutido com a polícia as reivindicações e as possíveis soluções para os problemas de segurança pública das comunidades. Podemos dizer, ainda, que esse trabalho é o núcleo da proposta de cidadania da SSPDC, que criou em sua estrutura administrava uma Diretoria de Cidadania, responsável pela coordenação das atividades de criação e acompanhamento operacional dos CCDS (ver Brasil, 2000, p. 185). 
a responsabilidade de um secretário de segurança pública, o comando da PM não estava submetido a tal secretário, mas ao Ministério do Exército e, no plano estadual, tratava diretamente com o governador e não com seu secretário de segurança pública (que administrativamente lhe era superior). No caso do delegado-geral da PC, quando precisava resolver um problema administrativo ou político, ia ao secretário de segurança que, por sua vez, ia ao governador. Há de se destacar que, com certa freqüência, o secretário de segurança pública estava vinculado à PC, o que não significa afirmar que, nesse período, no Ceará, militares não tenham assumido a função de secretario de segurança pública, como ocorreu com o general Assis Bezerra do Exército, secretário de segurança pública do governo Virgílio Távora (1979-1982).

Enfatizamos é o fato de a segurança pública, na prática, ter dois comandos, um civil e outro militar. O secretário de segurança, sendo um civil, acabava, de fato, sendo apenas o chefe da PC. O testemunho de um coronel da PM nos parece bastante esclarecedor ao dizer que, durante este período, o Estado Maior da PM organizava suas ações de forma autônoma, sem interferência direta do secretário de segurança. Ele relembra essa época como um bom período para a PM, pois, em suas palavras, o secretário de segurança, quando muito estudava um problema estratégico com os PMs (com esta afirmação, o coronel queria marcar a distância do secretário em relação às decisões tomadas pela PM).

Outra característica do regime militar, no que diz respeito às duas polícias, tem relação com a luta pelo poder entre delegados e oficiais da polícia militar. Antes de 1964, a prerrogativa de "autoridade policial" era apenas do delegado. A partir de 1967, tal prerrogativa passou a ser partilhada com o oficial militar.

Não foi raro, durante este período (que vai até 1988), encontrar rusgas entre PMs e PCs, ambos disputando espaços de poder e autoridade. Não significa dizer que, hoje, as desavenças tenham acabado, elas existem 
"sob controle" tanto na capital quanto nos outros municípios do Estado. No passado recente, PMs faziam prisões e queriam que os delegados fizessem o flagrante, e estes, às vezes, recusavam-se (por motivos legais), engendrando conflitos entre as partes. Nos vários municípios do Estado, era comum encontrar, em pequenas cidades, um oficial da PM (e por vezes um sargento ou mesmo um cabo) ocupando o lugar do delegado de polícia, ou seja, fazendo as vezes de delegado de polícia por falta de delegados 5 . Esta usurpação sempre incomodou a Polícia Civil e a Justiça e se tornou mais visível quando o Ministério Público e os juízes, com a Constituição de 88, passaram a não mais aceitar inquéritos ou investigações policiais feitas por PMs. Por outro lado, alguns comandos da PM achavam que o Estado, com exceção de Fortaleza, era de suas responsabilidades e não queriam que os civis chegassem por lá. Um bom exemplo dessa situação é o fato de termos 134 municípios cearenses sem delegados de polícia, ou seja, dos 184 municípios do Ceará, apenas 50 contam com delegacias de polícia (Fonte: Comissão de Direitos Humanos e Cidadania da Assembléia Legislativa do Estado do Ceará).

Na capital, muitos PMs faziam, e ainda fazem, trabalho de investigação, sobretudo os da 2a Seção da PM (P2) ${ }^{6}$, paralelamente aos trabalhos de investigação desenvolvidos pela Polícia Civil, chegando mesmo a gerar atritos entre as duas corporações por invasão em suas áreas de atribuições. Hoje, com a proposta de integração das atividades da PM com a PC, há uma

\footnotetext{
5 Em 1999 a SSPDC fez concurso para os cargos de delegado de polícia e escrivão. Foram aprovados 199 delegados e 351 escrivães e empossados 181 e 232 respectivamente. O fato é lembrado como um marco na administração do secretário de Segurança Pública, gen. Cândido Vargas de Freire, considerando-se que há 19 anos não se fazia concurso para o cargo de delegado de polícia civil no Ceará.

6 A Segunda Seção (2a Seção) ou Seção de Informações do Exército serviu de modelo para a 2a Seção da Polícia Militar ou P 2. Para alguns, suas funções hoje seriam investigar o contigente policial da PM, mas, no Ceará, ele vem desenvolvendo trabalho de investigação policial integrada às atividades da polícia civil, como se pode constatar nas atividades policiais das delegacias de polícia. No regime militar, os DOI-CODI estavam vinculados aos chefes do Estado-Maior e atuavam por meio da $2^{\text {a }}$ Seção (Couto, 1999). A 2a Seção continua sendo uma polícia política, como na época do regime militar, uma situação que não pode ser tolerada no Estado Democrático. A Casa Militar do Ceará está transformada numa polícia política para contenção dos movimentos sociais e para uma violenta e brutal ação de repressão às reivindicações mais justas da população, sobretudo das populações rurais... Essa é uma ação que tem um comando político tático, estratégico e ação de campo... São ações de plena consciência do governador e com a conivência, aval e autorização dele (Mário Mamede, 1999. In: Brasil, 2000, p. 138).
} 
certa parceria entre os serviços de informação da PM com os serviços de investigação das delegacias de polícia. Aqui, como no resto do País, a inexistência de um serviço de inteligência policial é uma realidade. Diante deste fato, houve uma iniciativa importante da atual Superintendência da Polícia Civil do Ceará: a criação do Departamento de Inteligência da Polícia Civil - DIP - para organizar e coordenar o seu serviço de inteligência investigativa.

Neste desenho contextual, não se deve esquecer o fato de a PC ter uma tradição cultural diferenciada da PM, marcada principalmente pelo jogo de forças políticas. Há que se destacar o fato de que as amizades políticas e as relações privadas influenciaram de forma vigorosa as carreiras na PC, considerando que, do ponto de vista da prestação de serviços, nunca foi muito diferente das outras categorias de servidores públicos com suas virtudes e mazelas. Outra tradição marca de forma bastante radical a PM: a formação militarizada, assentada na rigidez verticalizada de sua "hierarquia e disciplina". Um instituto que é quase um Estado dentro do Estado quando seus regulamentos e estatutos são um flagrante desrespeito aos direitos fundamentais e, portanto, um atentado contra o Estado democrático de Direito. Durante o período ditatorial, a partir de 1964, estas características eram ainda mais reforçadas.

Esse quadro não se propõe a ser exaustivo, pelo contrário, ambiciona apenas indicar que as PMs e PCs no Ceará não tinham, em sua história recente, grande tradição de colaboração e trabalho harmônico, sem esquecermos que são organismos que possuem tradições e culturas diferenciadas, com academias separadas, formações e inserções nas políticas de governo bastante distintas. 


\section{As atribuições das polícias civil e militar}

As atribuições das duas polícias são reafirmadas com a Constituição de 1988. Basicamente, nada muda. Cabe à PM atuar antes de o crime acontecer, com homens fardados e ostensivamente armados nas ruas, com a intenção deliberada de inibir, mas também reprimir o crime. É o chamado policiamento "ostensivo fardado", protegendo a vida, guardando os bens públicos e privados e garantindo as instituições da sociedade civil.

A PC, por sua vez, realiza o trabalho de "polícia judiciária", ou seja, ela investiga a autoria dos crimes e delitos praticados, através de um inquérito policial que é presidido por delegado de carreira. A investigação policial tanto pode ser iniciativa própria da PC como provocada pelo Ministério Público.

Ocorrido um crime, o PC deve realizar o inquérito policial. Ele o faz à paisana (já o PM deve estar caracterizado pelo fardamento policial) e, muitas vezes, o trabalho de investigação de um crime ou de prevenção deve ser sigiloso, sendo imprescindível uma polícia descaracterizada. O delegado, como presidente do inquérito, convoca testemunhas, ouve depoimentos, levanta indícios, faz a reconstituição do ocorrido, enfim, monta o inquérito (subsidiado nos instrumentais técnico-científicos da investigação) e o remete ao Ministério Público que, diante das provas e dos indícios apresentados no inquérito, poderá denunciar ou não os acusados e envolvidos ao Judiciário.

De uma maneira simplista, pode-se dizer que a PM atua antes do crime (reprimindo e prevenindo). À PC, em termos, cabe agir depois de ocorrido o crime, o que não exime a PC de também prevenir o crime, e o faz ao realizar a vigilância dos espaços públicos, pois ela é polícia de inteligência com capacidade e dever de se antecipar ao crime. São, sobretudo, corporações com funções complementares e por vezes diferenciadas. 


\section{O surgimento do Distrito-Modelo}

O DM foi criado em 1997, dentro de uma nova política de segurança pública ${ }^{7}$. Sua implantação pressupõe uma experiência bastante inovadora, haja vista propor uma integração das PMs e das PCs nos DMs. Dito de outra maneira, o Estado do Ceará inova em relação ao trabalho das polícias; considerando, hoje, o impedimento legal de se realizar a unificação das polícias, trabalha com a possibilidade real de integração das atividades policiais sob um comando unificado. Esta política de parceria entre as duas corporações policiais vai-se dar de várias maneiras, no entanto, para efeito de análise dessa parceria, trataremos a seguir apenas de dois destes aspectos.

O primeiro trata do trabalho integrado da PM (através das suas companhias), do CMB (através dos seus grupamentos de incêndio) e da PC (através das delegacias de polícia) dentro da área que compõe o denominado Distrito-Modelo.

O segundo aborda a presença de PMs dentro das delegacias distritais nos DMs. Uma decisão político-administrativa do governo estadual e do comando da segurança pública que, de certa forma, vem suprir, como veremos, a carência de PCs nos DMs acaba sendo uma reedição dos PMs dentro das delegacias de polícia, não mais no papel de "delegados" como no passado recente, mas sob o comando de um delegado de polícia: não

\footnotetext{
7 Esta política de segurança pública compreende as reformas e mudanças implementadas nos dispositivos policiais do Ceará pelo Governo Mudancista, a partir do segundo mandato do governador Tasso Jereissati (1995-1998) e nos primeiros dois anos do seu terceiro (1999-2002), por considerarmos que nesses treze anos (1987-2000) do Governo das Mudanças, no Ceará, há um mesmo processo político em andamento, mesmo sem desconsiderarmos as diferenças e as descontinuidades operadas pela maneira de gerir a coisa pública de cada governante instalado no palácio do Cambeba nos últimos quatorze anos. Dentro deste período, as reformas e mudanças compreendem, no primeiro momento, a nomeação, pelo governador TJ, de uma "Comissão Especial", sob a presidência do Procurador-Geral da Justiça, para apurar as denúncias do "Caso França", seguida da decisão político-administrativa do governo de criar a SSPDC e de unificar o comando da segurança pública no Estado. Depois, a criação e o desenvolvimento de mecanismos institucionais de descentralização, controle e fiscalização, como a Corregedoria Geral dos Órgãos de Segurança Pública e Defesa da Cidadania, os Conselhos Comunitários de Defesa Social, a Ouvidoria Geral do Estado, o Conselho Estadual de Direitos Humanos e o Centro de Apoio Externo e Controle da Atividade Policial. No segundo momento, as ações governamentais se voltam para a contratação do projeto de consultoria externa, de Mister William Bratton, que norteou o projeto de execução e implantação dos Distritos-Modelo e reforçou a implantação do projeto de modernização e informatização do sistema de segurança pública do Estado, coordenado pela Diretoria de Tecnologia da Informação da SSPDC, através do uso de tecnologias de satélite, fibra óptica e radiocomunicação. O terceiro momento é a tentativa do comando da segurança pública em estabelecer canais de articulação e participação comunitária com o policiamento através da criação e disseminação dos Conselhos Comunitários de Defesa Social- CCDS por todo o Estado do Ceará (Brasil, 2000, p. 219-20).
} 
estarão mais na situação de substituição de um PC por um PM nas funções de polícia investigativa, mas na de auxílio "legítimo" das atividades policiais realizadas por uma delegacia numa determinada área - assim como causador de polêmicas, considerando que nem todos os segmentos da segurança pública vão considerar "legítimos" os serviços prestados por PMs nas delegacias de polícia.

\subsection{O trabalho integrado}

Em tese, para que a política de integração das duas polícias possa funcionar, é necessária uma colaboração entre as cúpulas das PMs e das PCs dentro do espaço do DM e fora dele, ou seja, que os comandos assumam, na prática, a integração. Neste caso, os DMs compreendem a operacionalidade das atividades policiais desenvolvidas de maneira integrada entre as delegacias distritais, as companhias da PM e os grupamentos de incêndio do CBM que os compõem em cada área. Nas áreas pesquisadas, nossa equipe teve a oportunidade de presenciar diferentes operacionalizações deste modelo de integração da PC com a PM e o CBM.

No decorrer da pesquisa de campo que realizamos em alguns distritos policiais, tanto nos foram relatadas por policiais como pudemos presenciar, através da observação direta, as atividades realizadas com a participação das três corporações. Um bom exemplo são as reuniões entre os delegados com os oficiais e comandante da PM e do CBM nas áreas de abrangência dos DMs. Nessas reuniões, os oficiais e os delegados de polícia traçam planos de combate e prevenção ao crime. As estatísticas produzidas através dos relatórios de crime (RCs), feitos com base nos boletins de ocorrência policiais, são analisadas e, em função dessa análise, um plano de ação é estrategicamente desenhado. Um dos delegados de um DM pesquisado narra sua experiência:

semanalmente, temos uma reunião com o comandante da cia., juntamente com os outros dois delegados; 
nós, os três delegados e o capitão, vamos analisar o que aconteceu durante a semana, o que passou, e vamos olhar através de uma estatística (...) a gente olha o que a gente pode melhorar; identificamos às vezes até alguns meliantes, dada a descrição feita pelas informações dos relatórios e montamos um trabaIho para diminuir aquela criminalidade; acredito que o distrito modelo traz essa aproximação da atividade preventiva da polícia militar com a polícia civil.

Significa dizer que os responsáveis por um determinado DM, pela regularidade estatística apontada, sabem que tipo de crimes e delitos estão ocorrendo no bairro " $\mathrm{X}$ " com maior freqüência que nos outros e, pela caraterística de ação dos delinqüentes, é até possível, em alguns casos, se o delinqüente já possui passagem na delegacia, identificá-lo. As estatísticas orientam as estratégias de ação da PC e da PM naquela área da cidade ou seja, indicando, se preciso, maior presença ostensiva da PM, "saturando" o local para inibir e combater o tipo de criminalidade que vem sendo praticada, e o modo como a PC deve também direcionar suas investigações. A delegacia-pólo ${ }^{8}$ bem como a companhia do DM são responsáveis pela produção das estatísticas em suas áreas.

Outro exemplo: quando se dispõe de estatísticas do ano anterior, é possível prever onde acontecem os eventos que mobilizam a população, e qual foi o tipo de delito mais ocorrido (no ano anterior); dessa forma, é possível, no ano em curso, preparar ações específicas e conjuntas da PM e da PC, objetivando combater os delitos e crimes mais comuns numa determinada área naquele período correspondente.

Numa delegacia policial pertencente ao mesmo DM que pesquisamos, foi possível presenciar a montagem de uma ação conjunta de limpeza dos

\footnotetext{
8 A delegacia-pólo é a delegacia na área do Distrito-Modelo que funciona 24 horas porque nela funcionam os plantões policiais, ou seja, após o expediente normal, a delegacia-pólo mantém um sistema de plantão permanente com outras equipes de policiais plantonistas. Há muitas reclamações por parte da população no que diz respeito ao pouco número de delegacias plantonistas, uma vez que elas estão concentradas em bairros eqüidistantes, obrigando, muitas vezes, uma pessoa a percorrer longas distâncias para registrar a ocorrência policial nas delegacias plantonistas.
} 
xadrezes da referida delegacia. A limpeza fora proposta por um oficial militar integrante da companhia da PM pertencente ao DM da referida delegacia. Havia expressamente um desejo de colaborar para que a delegacia pudesse ter melhores condições físicas de funcionamento, de apresentação. Nesse DM, um dos delegados reúne-se diariamente com o comandante da companhia da PM. Ele conta que "todos os dias tem uma reunião" com o capitão da companhia da PM de seu DM; conta ainda que o encontro acontece na sala de um dos dois, para "que se possa agilizar os trabaIhos" do DM. Em outro momento, numa outra delegacia do mesmo DM da pesquisa, pudemos presenciar ações integradas da PM e da PC na investigação, perseguição e prisão de uma quadrilha após a realização de um assalto a banco no centro de Fortaleza. Os integrantes da quadrilha vinham sendo observados (monitorados) por uma equipe de PMs e PCs sob a coordenação de um delegado na área do DM em que estávamos realizando a pesquisa. Não sabíamos do fato, só tomamos conhecimento da operação após a prisão dos assaltantes. Um dos assaltantes, um PM, foi preso durante a perseguição policial em via pública em direção à área do DM, e o outro, quando já se encontrava na área do DM, em sua residência, tentou fugir ao perceber a aproximação da polícia, mas acabou dominado e preso pelos policiais.

O outro pilar do DM encontra-se, como dito, na cooperação das lideranças comunitárias nas atividades policiais. Se as estatísticas são informações objetivas extraídas dos Relatórios de Crimes feitos nos DMs, as lideranças comunitárias seriam responsáveis pelas informações subjetivas, obtidas pelo conhecimento prático que estas têm do bairro onde moram e da convivência diária com sua população. Na realidade, as informações dadas por essas lideranças e até as informações anônimas fornecidas por populares através do teledenúncia da polícia são de grande importância para que os delitos ocorridos dentro das áreas de atuação dos DMs sejam mapeados, e seus autores identificados e investigados (sem esquecer que, 
por uma razão ou outra, muitos dos crimes ocorridos não se transformaram em queixa-crime e passam a integrar as chamadas cifras negras). Para que os DMs funcionem como previsto, é necessária não só integração da PM com a PC no dia-a-dia das sua atividades, exigindo-se também participação e cooperação da comunidade em toda essa integração.

No que diz respeito às reuniões entre os comandos das polícias que compõem os DMs bem como destas com as lideranças comunitárias, há diferenças de comportamento. Como já citamos, há delegados que participam ativamente das reuniões dos DMs (tanto entre cúpulas como com as lideranças comunitárias). Há, porém, delegados resistentes que não acreditam neste expediente e não vão a essas reuniões ("isso é bobagem, não é assim que se combate o crime"). Isso inviabiliza toda a parte de planejamento estratégico da delegacia em questão e nega totalmente a possibilidade real de participação da comunidade através de suas lideranças neste processo de integração que, sem a cooperação e parceria com a comunidade, é um tiro no pé.

Alguns tomam uma posição intermediária, mandando um subordinado representá-lo, o que de certa forma esvazia a política de integração do DM, sem, no entanto, negá-la expressamente. Essa posição tanto pode ser assumida em relação às reuniões da cúpula quanto às reuniões com as lideranças. Conversando com pessoas do segundo escalão das delegacias sobre o que pensam dos DMs, no que diz respeito às reuniões com as lideranças comunitárias, ouvimos afirmações a indicarem que a participação dessas lideranças deveria restringir-se a prestar informações à polícia sobre quem são os "bandidos" do bairro para que a polícia possa identificá-los e prendêlos ou de uma maneira mais explícita dizem: se pelo menos eles servissem para denunciar bandido... eles só querem é falar mal da polícia.

De uma forma geral, os oficiais militares assumiram com maior afinco a política de ação do DM (engajando-se nas reflexões, tornando disponíveis oficiais para coordenar as reuniões com as comunidades, "empres- 
tando" PMs para as delegacias, etc.) do que alguns delegados de polícia. A tradição de obediência e hierarquia da PM facilita mais seu engajamento nesta dinâmica. Claro que esta não é a única explicação, haja vista que deve ser levado em conta ainda o fato de a PM ter um efetivo consideravelmente maior do que o da PC e que, de certa maneira, é mais fácil deslocar PMs para suprir deficiências em outros locais como as delegacias de polícia. Ouvimos algumas vezes também que a PM tem tendência a assumir lugares deixados vagos pela PC e que, no caso dos DMs, este fenômeno estaria acontecendo de forma massificada. Dito isso, é necessário acrescentar que também encontramos oficiais relutantes e até contrários ao deslocamento de PMs para desenvolver atividades policiais nas delegacias de polícia. No entanto, de uma forma geral, a PM acabou por ser a grande mola-mestra da dinâmica dos DMs, assumindo a programação e mesmo a coordenação das reuniões com as lideranças comunitárias; sua presença é sempre de destaque, enquanto a PC tem assumido, na maioria das vezes, uma postura de coadjuvante.

Algumas de nossas fontes chegam a dizer que os PMs se submeteram com mais aplicação e determinação à política do DM, haja vista que o atual secretário de segurança é um general (mesmo que nem todos aceitem de bom grado a presença de um quadro do exército - stricto sensu no comando da Secretaria de Segurança, preferindo ver um quadro da PM no posto). Uma vez que a autoridade a que estão submetidos é considerada legítima, eles têm maior propensão a se submeter às ordens dadas (estamos em um espaço social marcado pela idéia de "hierarquia e disciplina"). Em relação à obediência (às ordens do secretário ou a outra autoridade qualquer), os PCs são mais autônomos e "anárquicos".

Estas diferentes posições dos diversos agentes que compõem as cúpulas dos DMs deixam pairar sobre a dinâmica uma dúvida sobre seu funcionamento futuro. Os policiais favoráveis à política do DM ficam apreensivos sobre o futuro desta política de segurança pública a partir do final 
de 2002, quando será encerrado o mandato do atual governo do Estado. Eles se perguntam sobre o interesse que os próximos mandatários terão em manter funcionando este aparato. Enquanto alguns se interrogam sobre a possibilidade de o próximo governo dar continuidade à política do DM, outros acreditam que este é um caminho sem volta e chegaram a nos dizer que o atual governo já pensa em transformar em lei o projeto de criação dos DMs. Afinal, não podemos deixar de ignorar a irracionalidade dos governos ou determinados governantes quando assumem o poder frente aos projetos político dos antecessores e/ou adversários políticos, desconhecendo até mesmo a positividade e o ganho que estes possam representar como política pública para a população em geral.

Em todo esse processo, acreditamos ser fundamental o sentido de pertença da polícia com relação à comunidade em que presta serviço, e que esta mesma comunidade tenha respeito e confiança na sua polícia. Esta simbiose só será possível com uma polícia comunitária que esteja comprometida com o exercício legítimo da cidadania, fundado no respeito, na garantia e na promoção dos direitos humanos. Por um lado, não se pode negar a existência de dificuldades de ordem burocrático-administrativa e de carências de recursos de pessoal no interior das corporações policiais para a efetivação de polícia comunitária e, principalmente, das resistências silenciosas que há em determinados setores da comunidade e da polícia para essa efetivação. Por outro lado, não se pode negar a existência de experiências exitosas no contexto das sociedades democráticas, que reforçam a necessidade de a sociedade brasileira adotar o modelo da polícia comunitária como uma das pilastras de sua política de segurança pública, considerando, sobretudo, que o combate aos altos índices de violência social e de criminalidade só se faz com a participação efetiva da sociedade organizada. Sem ela, todas as ações estarão condenadas ao fracasso.

Faz-se necessário destacar que, no exercício da polícia comunitária, o PM de ponta se torna um agente autônomo e deixa de ser um 
Sociologias, Porto Alegre, ano 4, no 8, jul/dez 2002, p. 318-355

'mero cumpridor de ordens', este passa a exercer, sob supervisão, as tarefas de identificar e analisar problemas, organizar a comunidade, planejar e implementar soluções. É um modelo que valoriza, portanto, a descentralização decisória, a autoridade e competência dos agentes de ponta, a flexibilidade do controle interno e a atenuação das distâncias hierárquicas tradicionais. Esse princípio descentralizador não objetiva questionar ou destruir a estrutura verticalizada própria à corporação militar, mas sim: 1- possibilitar o trabaIho interativo dos policiais junto à comunidade civil; 2- modernizar a cultura institucional, num sentido análogo ao que tem orientado mudanças em outros tipos de organizações hierárquico-burocráticas, isto é, diminuindo as causas de ineficiência decorrentes da rigidez regimental, da excessiva centralização, da multiplicação de graus e procedimentos associados à tomada de decisôes, assim como da 'mentalidade de casta' que tradicionalmente vigora em tais organismos (Muniz et al., 1997, p. 204-5).

E no caso específico da PM, que possui um capital simbólico assentado no prestígio hierárquico e no controle da rígida disciplina, operado pelos seus escalões superiores, guardiões e produtores de corpos dóceis e úteis, a polícia comunitária significa a ruptura com os 'excessos de um militarismo'que cheira a decomposição na ordem democrática.

\subsection{Os PMs e PCs numa Delegacia de Polícia: os interesses em questão}

Para tentar dar conta das representações e das práticas policiais integradas de PMs e PCs nas delegacias que estão dentro dos DMs, apresentamos os depoimentos de alguns PMs e PCs sobre suas atividades, as queixas e reclamações que apresentam e as situações que lhes parecem benéficas e que são apontadas como fruto do DM. São os benefícios mútuos, retira- 
dos desta parceria chamada integração, que nos parecem responsáveis por sua resistência contra as denúncias de ilegalidade feitas contra ela. Frisamos que não estamos apresentando essas representações como realidades objetivas, mas, como fruto de percepções subjetivas de ambas as partes, que ganham maior entendimento à luz do que anteriormente foi dito.

Apresentaremos a seguir alguns temas que dizem respeito ao trabaIho da polícia judiciária, à carga de trabalho das corporações civil e militar e à maneira como se inscreve o trabalho das mulheres dentro das delegacias. O objetivo, mais uma vez, não é ser exaustivo, tampouco apontar com o dedo para as práticas policiais. O que se tem como meta é dar uma idéia das relações e dos interesses que ambas as partes retiram destas atividades conjuntas de integração.

\subsubsection{A carga de trabalho: PCs versus PMs}

Segundo os PMs, os policiais civis não têm a mesma carga de trabaIho que os policiais militares que trabalham dentro das delegacias dos DMs. Vários PMs chegam a dizer que trabalham muito mais que os civis. Nos "dizeres" dos militares, os civis só vão trabalhar quando querem, querendo dizer com isso que os PCs são mais autônomos para se ausentarem do trabalho para realizar tarefas de interesse particular ou por outro motivo qualquer. Alguns PMs contam que poucos policiais civis trabalham os dois expedientes. É sabido que muitos estudam e alguns têm outra "viração" ou "bico". Dizem ainda que os delegados gostam de trabalhar com os militares, pois estes são mais disciplinados, obedientes e não faltam ao trabalho; chegam mesmo a afirmar que eles, PMs, são mais educados quando recebem a população.

Os PMs denunciam, ainda, que muitas policiais (PCs) se recusam a fazer trabalho de rua: operam unicamente realizando trabalho administrativo (para o qual não foram contratadas com exclusividade). Dizem que "os delegados não conseguem obrigá-las" a trabalhar em suas funções (para alguns policiais, a situação é até cômoda, porque em determinadas situa- 
ções mulher só atrapalha). Com efeito, conversamos com algumas PCs e elas dizem sem constrangimento que não foram feitas para aquele serviço, que preferem dar dois expedientes fazendo trabalhos burocráticos a ter de arriscar a vida com uma arma na mão. Não podemos dizer que esta seja uma regra geral no caso das policiais, considerando que muitas mulheres na PC são titulares em suas delegacias e assumem lado a lado com os policiais civis e militares os trabalhos operacionais e de enfrentamento da criminalidade no dia-a-dia das ruas, fora dos muros das delegacias.

No caso das policiais que se negam a fazer atividade policial fora da delegacia, é uma situação socialmente aceita dentro da delegacia, haja vista que ela está em sintonia com o papel socialmente esperado das muIheres (não-violento, se considerarmos a violência que envolve o uso da força policial) em nossa sociedade. Além disso, elas acabam suprindo carências humanas em outras áreas da delegacia (o trabalho burocrático). Os PMs também acabam realizando o serviço burocrático da delegacia, quando é necessário, pelo fato de que sua presença dentro das delegacias acaba permitindo que as PCs possam deixar este tipo de atividade nas mãos dos homens para se dedicarem às atividades de investigação.

Alguns PMs dizem ainda que todos (os civis) têm outro trabalho, que ganham por fora (um é dono de uma loja, outro tem uma concessionária ou é vendedor de carros, etc.). Em uma das delegacias, alguns PMs relatam que apenas o delegado titular vem todos os dias e trabalha os dois expedientes, e que muitos delegados adjuntos só vêm um período.

Um dos PMs entrevistados disse que seus colegas civis, quando dão plantão, só trabalham 3 vezes por semana (na realidade, um plantão de 24 horas implica 72 horas de folga). Em algumas delegacias, os PMs acabam por manter um ritmo de trabalho próximo daquele levado dentro da caserna, ou seja, quando "tiram um plantão" no quartel (mesmo com direito a 72 horas de descanso), não raro passam o período de "repouso" dentro do próprio quartel. Nas delegacias onde prestam serviço, acabam por estar no 
trabalho antes de findo o tempo de que dispõem para compensar o plantão dado (um PM nos disse que ele, às vezes, dobra os plantões a pedido do delegado). Os PMs parecem passar menos tempo em casa, aproveitando seu período de repouso, do que seus colegas civis. No entanto, caso estivessem aquartelados e não em uma delegacia de polícia, o tempo de repouso seria ainda menor. Assim, acabam por ganhar na troca e não querem de maneira nenhuma retornar aos quartéis.

De uma forma geral, os PMs estão mais disponíveis para o trabalho que lhes é pedido pelos delegados. Participam (segundo eles mesmos) das blitze com maior presteza do que os civis, principalmente porque esta tarefa é bem familiar como atividade de policiamento ostensivo militar no espaço público. Alguns PMs dizem que certos PCs se recusam a participar das blitze (eles só vão quando querem, diz um; o delegado tem dificuldade em mobilizar os civis para as blitze, diz outro que também informa: tem civil que não gosta de trabalhar de noite). Os PMs falam ainda que vão para as blitze sempre que pedem, pois eles não podem desobedecer. Os PMs trouxeram para as delegacias sua cultura de obediência, sem questionamento, à ordem dada. A "ordem estabelecida" tem sabido tirar proveito disso, uma vez que, pela disciplina e obediência às ordens dadas ou solicitadas pelos delegados aos PMS que prestam serviços nas delegacias de polícia, estes acabam por conquistar a proteção e confiança dos delegados, ou seja, existe uma determinação do comando militar que diz que um PM só deve ficar de 3 a 6 meses numa delegacia de polícia e que, terminado esse período, deve ser reintegrado à sua tropa (para que não tenha sua formação descaracterizada), mas, pelo que ficamos sabendo, muitos PMs estão nas delegacias há anos por interferência dos delegados junto aos comandos militares. Há que se considerar aspectos importantes como a necessidade de uma equipe policial entrosada e conhecedora de sua área de atuação, para a realização de ações policiais inteligentes e efetivas na prevenção e na repressão ao crime. 
Outra afirmação dos PMs sobre o trabalho nos DMs diz respeito à inserção deles na estrutura: quando chegam, eles recebem tarefas específicas, mas, à medida que o tempo passa e que são constatadas capacidades no PM para realizar determinado tipo de trabalho para o qual ele não foi treinado ou mesmo indicado, os civis começam a "empurrar" novas tarefas para eles. Segundo um PM, no DM o ideal é você "ficar quieto" e não parecer "muito sabido", senão "eles montam" (querendo com isso indicar que o soldado da polícia pode ser explorado por um colega civil). Ele diz ainda: aqui é melhor você não aprender coisa nova senão os outros mandam você fazer; eu cheguei para fazer serviço burocrático e hoje estou fazendo de um tudo por aqui. Um dos PMs explica que, quando chegou na delegacia, atendia sempre aos seus colegas civis, haja vista que estava contente de estar trabalhando como civil e que, por temer perder o lugar, sempre obedecia. Quando notou que estava sendo explorado, disse que começou a dizer não, quando pode. Diz, entretanto, que sempre obedece ao delegado.

Nessa questão, os sindicatos dos policiais civis têm dito publicamente que os delegados têm aceito a ilegalidade dos PMs trabalharem nas delegacias de polícia não só pelo déficit de pessoal da PC (ou até porque não quer se opor ao comando da SSPDC), mas porque os PMs não questionam ordens superiores como os PCs e chegam a dizer de maneira ácida que é melhor trabalhar com quem obedece sem questionar do que com quem questiona, afinal, a cultura da caserna não permite que o PM pense, diferente do policial civil que pensa nas ordens que recebe dos superiores e pode até questioná-las se achá-las indevidas ou ilegais.

\subsubsection{O trabalho da polícia judiciária}

Outro ponto de choque de opinião entre as duas corporações diz respeito ao trabalho de polícia judiciária, constitucionalmente reservado à polícia civil. Ambas as partes vão falar em causa própria: os PCs explicando 
que apenas eles são capazes de fazer tais trabalhos, e os PMs argumentando que podem ser tão bons quanto os civis nos trabalhos de investigação; a 2a Seção da PM parece ser a fonte dessa experiência.

No que diz respeito a este ponto, os policiais civis têm os textos legais do seu lado e encontram-se em uma posição simbólica privilegiada para afirmar uma superioridade técnica ante os PMs: dizem que estão mais bem preparados para investigar do que os PMs, por terem feito curso específico, porque a "lei diz", etc. e tal. Os PCs pouco discutem essa questão pois estão imbuídos de certeza quanto a quem deve fazer o que e como. Os PMs quando falam sobre o tema, fazem-no discretamente, pois sabem que legalmente apenas os PCs estão habilitados para tal tarefa. No entanto argumentam que, na PM, existem policiais também treinados para o trabalho de investigação (pensamos que eles aqui fazem referência à 2 a Seção da PM que, na época da repressão, teve experiência com serviços de informação semelhantes aos do Exército).

O grande argumento dos PMs quanto à legitimidade de seu trabalho nas delegacias (além de registrar Boletins de Ocorrências - BOs - e fazer outros trabalhos burocráticos, mais "apropriados para um PM", no dizer de um policial civil) dá-se no fato de eles "aprenderem a fazer fazendo". Argumentam que os PCs, quando chegam às delegacias, "pouco ou nada sabem" e que eles aprenderam o ofício de polícia aos poucos. Os PCs reconhecem que o trabalho de polícia se aprende com o tempo. Sobretudo os mais antigos vão afirmar isso. Até porque isso corrobora a posição de dominação que estes mantêm dentro da polícia civil ao afirmarem: os mais antigos são melhores policiais. Ora, é exatamente sobre esta lógica que repousa a afirmação de alguns PMs: o trabalho dentro da delegacia ensina aquilo que eu não sei.

Por fim, podemos dizer que de uma forma geral, os policiais das duas corporações parecem manter um bom relacionamento na integração de suas atividades nas delegacias de polícia. As disputas são vistas apenas 
quando tocam nestes dois pontos delicados: a capacidade dos PMs em fazer um serviço específico dos PCs (que suscita opiniões simetricamente opostas em função daquele que emite a opinião) e a assiduidade e o empenho dos policiais civis no exercício do trabalho cotidiano (por sinal, os PMs nunca fazem este tipo de observação diante de um policial civil).

\section{A delegacia de polícia: inferno e paraíso para o PM}

A grande maioria dos PMs que entrevistamos nas delegacias distritais, sob as ordens de um delegado, parece estar "muito contente" com a nova situação. O trabalho nas delegacias lhes parece muito mais interessante do que aquele que desenvolvem nos quartéis. Chamamos atenção para o fato de que a distinção entre as duas corporações raramente foi feita baseada no tipo de trabalho prestado, mas nas relações tecidas entre comandados e comandantes, ou seja, o que está sendo questionado pelos PMs não é o tipo de trabalho por eles desenvolvido como policiais militares e sim as relações militares de verticalização e rigidez da hierarquia e da disciplina, que são por eles consideradas arbitrárias, antidemocráticas, ultrapassadas, negadoras de direitos fundamentais e, muitas vezes, humilhantes.

Efetivamente, durante nossa permanência junto aos policias nas duas corporações, pudemos perceber um uso radicalmente diferenciado dos conceitos de ordem, hierarquia e obediência. Tanto entre PMs quanto entre PCs, esses conceitos existem e são utilizados por comandados e comandantes de maneira diferenciada e até pessoal. No entanto o que está por trás da conceituação difere nos dois tipos de polícia.

Os PMs têm um regime disciplinar e hierárquico que deixa pouco ou nenhum espaço para aspirações individuais e para o questionamento de uma ordem dada, seja ela arbitrária ou não. Os delegados parecem levar em conta as aspirações de seus comandados, caso tenham expectativas de ver cumpridas suas ordens, ou seja, na PC existe uma margem de manobra muito grande entre a ordem dada e seu cumprimento imediato, sobretudo 
porque os delegados, segundo depoimentos, compreendem respeito à autoridade do seu comando com certa flexibilidade se considerarmos que não há a exigência do não- questionamento às ordens dadas aos subalternos. Há a possibilidade do estabelecimento do diálogo e até mesmo da discussão entre quem ordena e quem recebe a ordem - um cenário diferente, se comparado ao da PM.

Na PM estamos dentro do universo hermético e verticalizado pela rigidez de sua hierarquia e de seu código disciplinar, em que não se questiona uma ordem recebida de um superior hierárquico (ou pelo menos, como dizem alguns PMs e repetem alguns oficiais: ordem não se questiona, se cumpre). A PM tem instrumentos militares capazes de fazer seus soldados dançarem conforme a música (ou marcharem segundo o ritmo): prisão, suspensão de férias, ausência de promoções para os desobedientes, etc.

Já os PCs estão em uma situação trabalhista muito próxima daquela em que se encontram outros funcionários do Estado (sobretudo no que diz respeito à estabilidade de emprego). Podem questionar as ordens de seus superiores ou, pelo menos, são capazes de boicotá-las, caso não as considerem legítimas (não estamos aqui falando em legalidade, mas em legitimidade). Em caso de confronto entre chefes e funcionários, os subordinados que causam problemas são "deixados na geladeira" e, nos casos mais graves, transferidos para outros locais de trabalho. Não raro, na PC, sabemos que os delegados "causadores de problemas" ou aqueles considerados desafetos do grupo que está no comando acabam ficando sem qualquer função, no denominado "tapete verde". É, muitas vezes, uma prática que beira a irracionalidade, quando determinados policiais ficam afastados de suas funções, mas recebendo seus salários, pelo simples fato de terem uma ação na Justiça contra o governo estadual e, por esse motivo, se torna persona non grata, portanto, impedido de participar e contribuir com seu serviço na administração do aparelho policial. Esta prática não se restringe 
apenas à organização policial, é hoje uma prática corrente na administração pública cearense, adotada em larga escala pelo denominado Governo mudancista.

Esta situação é muito diferente daquela na qual se encontra o policial militar, que pode ser coagido por uma série de punições, mesmo em sua liberdade de ir e vir, caso descumpra ordens recebidas de seus superiores hierárquicos. Claro está que aqui apenas traçamos em linhas gerais a questão da ordem e da obediência na hierarquia das duas polícias, respeitando o fato de que a realidade é muito mais complexa; no entanto o objetivo aqui é apenas dar uma idéia das duas corporações, no que diz respeito a essas questões.

Assim, para os PMs, a ida para a delegacia é vivida como uma chance que lhes foi dada. Alguns policiais militares contam sem nenhum constrangimento a forma como chegaram às delegacias policiais dos DMs, relatando claramente que foram "indicados" por um amigo ou conhecido de amigo, ou por terem amizade e proteção dos comandos hierárquicos.

Estar na delegacia do DM aparece na fala dos PMs como uma melhora de vida (menos disciplina, ser tratado como gente pelos chefes, ter horários, folgas, férias, trabalhar à paisana, ser tratado como cidadão, não ser insultado, ninguém para gritar ou chingar com palavrôes por qualquer besteira, dependendo do humor dos comandantes da caserna). O DM, para os PMs que lá trabalham, é uma espécie de "prêmio" para os eleitos. Ninguém deseja voltar para o quartel. Sublinhamos, mais uma vez, que o que está em jogo não é, para a grande maioria, o trabalho específico que realiza numa ou noutra polícia, mas o respeito que recebe de seus chefes, "as regalias" de que desfruta dentro das delegacias (em relação aos seus colegas de farda que estão nas casernas). Esta situação parece poder explicar por que eles (PMs) se submetem às regras desiguais em comparação com os policiais civis. 
A presença dos PMs nas delegacias permite que alguns PCs não mais precisem fazer todo o serviço burocrático, dobrem plantão, estejam em blitz noturna, tenham de ir "para a rua" (ou seja, façam enfrentamento com bandido). Aqui aparece uma margem de manobra maior que é deixada para os PCs que não desejam cumprir a carga de trabalho. Esta margem de manobra é fruto da presença dos PMs nas delegacias de polícia.

Os PMs têm uma consciência muito viva destas desigualdades de tratamento entre eles e seus colegas civis. No entanto isso ainda lhes parece "menos ruim" do que a vida na caserna. Por sinal, a vida na caserna lhes está constantemente sendo lembrada, haja vista que suas férias só podem ser gozadas quando o superior militar autoriza.

É importante lembrar que os PMs têm regalias na delegacia, que a vida militar desconhece: poder ausentar-se para resolver problemas particulares durante o horário de trabalho, chegar atrasado ao serviço, não ser destratado na frente dos colegas pelos superiores, etc. Talvez um dos grandes privilégios seja fazer cursos ou estudar, caso o delegado seja favorável (lembramos que maior grau de instrução implica melhoria salarial). Muitos PMs entrevistados nas companhias da PM dizem que os oficias não gostam de soldado que estuda, e que a PM não favorece os estudos, considerando que os oficiais implicam com quem tenta estudar, etc. Os oficiais negam tais acusações e dizem que apóiam quem quer estudar. Fazem apenas uma ressalva: que não seja no horário de trabalho. Na PC, o estudo é visto como um investimento, e alguns PCs fazem cursos durante o horário de trabalho, o que é permitido pela legislação, com autorização do chefe imediato, e muitas vezes este chefe tem que determinar alguns policiais (para completar o número solicitado pela Academia) para fazer os cursos que são oferecidos pela Academia de Polícia Civil - APOC - porque estes, muitas vezes, não se sentem motivados.

Podemos dizer ainda que, para os PMs, ser considerado "pau-pra-todaobra" na delegacia parece ser menos traumático do que a vida aquartelada. Se 
pudéssemos resumir, diríamos: PM obedece sem traumas ao comando do delegado de polícia ou volta para o quartel. Por outro lado, esta relação não é tão sem traumas e dissensos, haja vista que fomos informados de que alguns PMs, em algumas delegacias policiais, foram devolvidos aos quartéis por "incompatibilidades", ou seja, acabaram gerando problemas para as atividades policiais nas delegacias e desobedecendo às ordens recebidas, ou seja, aos PMs não é permitida a (in)disciplina flexível e às vezes frouxa da PC.

\section{Os PMs na delegacia: um aliado de fato mas um concorrente simbólico}

Os policiais civis, de uma forma geral, aceitam a presença dos PMs dentro das delegacias, pois estes acabam preenchendo funções que eles, os policiais, preferem não realizar. Como muitos funcionários do Estado, de outras categorias civis, os PCs não se acham bem pagos pelo serviço que realizam. Neste caso preciso, argumentam que seu trabalho é ainda mais perigoso, haja vista estarem lidando com a morte e com a vida e que o salário que recebem não corresponde ao risco que correm.

O risco de vida não é a única reclamação que expressam em relação ao Governo do Estado (não são "tratados como cidadãos", não têm "aumento de salário", etc.). Em certo sentido, seu pleito é muito parecido com o de outras categorias de servidores públicos estaduais (dizem que o governador é um "ditador", que só "faz o que quer", que "não respeita o servidor público", "não respeita nem determinação da Justiça"...).

Reclamam da falta de concurso para policial civil (pois dizem ser poucos para as tarefas necessárias, denunciam o "descaso do governo com a diminuição de efetivos", etc.). E é aqui que as coisas se complicam, pois os PMs acabam sendo uma mão-de-obra ambígua: eles preenchem um espaço vazio e, ao mesmo tempo, realizam uma tarefa para a qual não foram preparados pela formação policial, nem estão amparados numa legislação para fazê-la. 
É, portanto, este um dos motivos pelos quais a presença de PMs nas delegacias policiais está sendo questionada por alguns PCs e, de maneira mais incisiva, pelos seus sindicatos. Os PCs consideram isto uma "falta de reconhecimento e consideração" para com habilidades específicas que apenas eles os civis - teriam para realizar o ofício de policial civil - serviço essencialmente investigativo. O fato de o Governo estadual e do comando da segurança pública colocar PMs para realizar funções específicas de PCs pode ainda ser visto como um descredenciamento dessas funções específicas e até uma perda de espaço de ação da PC na política de segurança pública do Estado.

Paradoxalmente o PM é bem recebido na delegacia. Dois argumentos servem para dar sustentação à política de boa vizinhança entre os policiais das duas corporações. O primeiro engloba todos e é expresso na idéia de que o PM é um policial como qualquer outro (somos todos policiais), e a população não quer saber se o policiamento é feito por PMs ou PCs, sua exigência é que sua segurança possa ser garantida pela polícia. No entanto nos parece que uma das razões mais pertinentes para a aceitação da parceria (e sobretudo, da ultrapassagem das querelas e lutas por poder e função) dá-se exatamente porque os PMs permitem aos civis uma divisão efetiva da carga de trabalho (que é percebida como maior do que aquilo que o salário retribui), ou seja, os PMs assumem uma parte do trabalho dos policiais civis, em tese e em direito, da alçada apenas destes últimos.

Em relação ao DM (e em particular quanto à presença dos $\mathrm{PMs}$ fazendo o mesmo trabalho do civil), podemos resumir a posição do policial civil como atravessada por uma tensão bipolar:

a) Se, por um lado, podemos perceber que o PM é bem-vindo, por ser um aporte em termos de material humano em um espaço onde o policial civil sente necessidade de reforços (além do que eles são "todos policiais"), o PM, de forma indireta, assume parte da carga de trabalho do PC (mesmo realizando funções não especificamente suas). Esta situação vai permitir que o policial civil realize um número de atividades extrapoliciais (aquilo que é conhecido no serviço público como "fazer macaco" ou 
"trabalhar por fora", realizando assim um complemento da renda mensal em uma atividade remunerada, durante o horário de serviço). Tudo isso sem comprometer o funcionamento da delegacia, haja vista que os PMs podem dar a cobertura para as escapadas.

b) Por outro lado, podemos perceber restrições aos serviços dos PMs, na medida em que eles realizam exatamente as tarefas de PCs (que pressupõem habilidades específicas), deslegitimando o pleito destes para que o Governo valorize as carreiras da polícia civil e abra mais vagas. $\mathrm{O}$ fato mesmo de os PMs realizarem tarefas civis indica que qualquer policial pode realizá-las, desvalorizando simbolicamente a carreira civil ou mostrando que os PMs são tão capazes quanto os PCs e podem até ser melhores para determinadas visões e objetivos de comando.

Por um lado, o PM aparece neste cenário como um aliado para o PC - ele permite que o PC possa aceitar com menor dificuldade a vida de policial que ele questiona em termos salariais. Por outro lado, este mesmo "parceiro", por sua presença na delegacia, fazendo trabalho de PC, torna ilegítima parte de suas reivindicações (se um PM pode fazer trabalho de PC, qual seria a necessidade de novos postos de trabalho na polícia civil? Não seria melhor deslocar PMs para estas funções?). Para os PCs, o pior cenário é uma polícia única, totalmente militarizada (e os serviços de polícia civil, realizados por PMs, abrem uma brecha nesta direção).

\section{Integração que afirma e nega a unificação}

É certo que os delegados de polícia gostam de trabalhar com os PMs, não só porque estes são efetivamente obedientes, disciplinados, faltam pouco ao trabalho, mas porque esses PMs nas delegacias permitem que os delegados melhorem o desempenho da delegacia ${ }^{9}$ sob seu comando. O PM acaba sendo um aliado, principalmente para o delegado, que conta

9 Se há mais efetivo disponível para as atividades de policiamento numa determinada delegacia, é inegável que o desempenho desta na resolução dos crimes pode aumentar, e os resultados desse trabalho de prevenção e repressão na área podem ser lidos nos índices das estatísticas por distrito policial. 
com sua ajuda irrestrita. Mesmo que ele seja uma figura que "questione" no plano teórico - os lugares estabelecidos pela legislação à polícia civil e militar, a presença de PMs na delegacia - no plano prático - permite a realização de tarefas que não seriam possíveis com o reduzido efetivo da PC nas delegacias policiais do qual dispõe o delegado. A realidade hoje é que, se os PMs saíssem das delegacias, estas fechariam por falta de efetivo para dar sustentação aos trabalhos de polícia judiciária.

Há que se considerar ainda outra faceta desta realidade chamada integração das polícias civil e militar: o fato de os comandos militares (apesar dos receios que sentem de que os PMs venham a ser "contaminados" pela convivência com os civis) apoiarem a experiência (apesar das resistências veladas ou não dos oficiais que se sentem perdendo poder de mando e controle dos subordinados, nesse cenário da integração) e de a PM estar efetivamente ocupando as brechas que vão encontrando nos serviços da PC com o seu considerável déficit de pessoal. De forma geral, os oficiais militares acreditam culturalmente que um "bom serviço de polícia" (qualquer que seja ele), passa antes de tudo pela disciplina (de preferência militar) e pela obediência à hierarquia verticalizada (à qual eles sabem que os servidores civis não se submetem). Se esse serviço pode ser prestado dentro da PC, por que não realizá-lo? É certo que alguns oficiais olham para este tipo de parceria integradora, realizada dentro das delegacias, como uma experiência capaz de orientá-los quanto ao futuro da corporação militar, numa unificação futura das forças policiais. Outros vêem como um apanágio capaz de evitar a unificação das polícias.

Em toda esta discussão acerca da experiência de integração das atividades da PM e da PC, independentemente da vontade de quem a conduz, ela quase sempre deságua na questão da unificação. No decorrer de nossa pesquisa, pudemos observar que sempre que se discutia a integração das atividades das polícias estaduais, o interlocutor militar ou civil, não raro, reportava-se de maneira enfática a favor da integração e não da unificação, 
fazendo questão de distinguir integração de unificação. Aqui se constata que não há uma defesa aberta da $\mathrm{PC}$, salvo algumas manifestações individuais, ou da PM pela unificação. E, no caso do comando da PMCE, o que temos visto é a defesa intransigente do comandante da PMCE, coronel Valdízio Vieira Silva, pela não-unificação, justificando que é preciso haver entre policiais a mesma especialização que há em outras carreiras como a de médico, advogado (Jornal O POVO, 28/01/02, p. 14). De certa maneira, este fato vem corroborar a opinião da deputada federal Zulaiê Cobra Ribeiro (autora de emenda constitucional que trata da unificação das polícias e que se encontra parada na Comissão Especial de Segurança Pública, da Câmara Federal desde junho de 1999), ao assinalar:

os comandantes militares não querem a unificação das polícias da forma que estou pleiteando: união das tropas civis e militares com formação civil e instrução militarizada. Ostentando altas patentes, eles fazem pressão sobre o Executivo e o Legislativo por temerem perder privilégios conquistados como oficiais. A tropa, que enfrenta as ruas e arrisca a própria vida e às vezes até mesmo a família para pegar bandido, deseja a unificação (Jornal O POVO, 05/02/02, p. 7).

Ainda, sobre a unificação, o então secretário de segurança pública do Ceará, general Cândido Vargas de Freire, diz que 'academicamente' defende a unificação, mas ressalta que aqui a integração das policias civil e militar já vem produzindo bons resultados (Jornal O POVO, 28/01/02, p. 14).

Com fundamento nos depoimentos de policiais militares e civis coletados durante a realização da pesquisa (através de entrevistas, oficinas e conversas informais) que fundamenta a discussão do presente artigo, podemos assegurar, sem medo de errar, que tanto a base da polícia civil como a da polícia militar não se sentem incomodadas com a unificação, e que a experiência da integração desses policiais no dia-a-dia das delegaci- 
as policiais é a prova incontestável dessa asserção. Há, contudo, uma crítica contundente, acerca da discussão em foco, feita por José Vicente da Silva Filho, que, de certa maneira põe os "pingos nos is", ao dizer que insistir em manter o sistema das duas polícias estaduais é preservar um acidente histórico, como se fosse lógica a convivência de duas organizações extremamente diferenciadas para cuidar do mesmo problema: controlar o crime. Vai mais longe ao afirmar que se insiste

na impraticável idéia de integração, ou seja, da cooperação eficiente das polícias. Nas polícias modernas, as funções de policiamento uniformizado e de investigação devem boa parte de seu êxito ao planejamento de ação conjunta, sob a responsabilidade de um único chefe. Institucionalizar essa integração num único corpo policial é a solução para a polícia sem adjetivos, nem militar nem judiciária. Não será fácil a transição para a nova polícia, mas não podemos enfrentar o crime do século XXI, cada vez mais organizado e ousado, com uma polícia ineficiente e cara com raízes no século XIX (Veja, 30/01/02, p. 93).

Ao final, não é incorreto afirmar que a experiência positiva ou não de integração das atividades policiais não encerra a necessidade de se alterar pela unificação o atual modelo das polícias estaduais. No caso da experiência positiva da integração, esta fortalece a tese da unificação pelo simples fato de comprovar que é possível integrar ações policiais a partir de um comando unificado, ou seja, a unificação da base funciona sem traumas quando o comando não está fracionado e não é divergente (no Ceará, observamos que as divergências têm sido contidas pelo comando único da SSPDC). Em toda essa discussão, não nos podemos esquecer de que se a PC pode "contaminar" a PM com o que tem de negativo e/ou positivo, o inverso também é verdadeiro. Esta é uma aposta que tem dois lados multifacetados e pode ser transformada numa estrutura miscigenada. Por outro lado, não podemos tampouco esquecer que, se as polícias civil e 
militar possuem capitais simbólicos e culturais específicos, têm em comum o capital da força física legal, um monopólio que lhe é conferido pelo Estado democrático de Direito, que tem como princípios a garantia, a defesa e a promoção da cidadania e dos direitos humanos.

\section{Referências}

BRASIL, M. G. M. A segurança pública no “Governo das Mudanças": moralização, modernização e participação. Tese (Doutorado em Serviço Social)- Programa de Estudos Pós-Graduados em Serviço Social. São Paulo: Pontifícia Universidade Católica de São Paulo, 2000. 325p.

BRASIL. Instituto Brasileiro de Geografia e Estatística. Censo Demográfico, 2000.

BRASIL. Ministério da Justiça Secretaria Nacional de Segurança Pública. Brasília: www.mj.gov.br/senasp, 2001.

BRETAS, M. L. Observações sobre a falência dos modelos policiais. São Paulo, Tempo Social, v. 9, n. 1, 1997, p. 79-94.

MUNIZ, J. et al. Resistências e dificuldades de um programa de policiamento comunitário. São Paulo, Tempo Social, v. 9, n. 1, 1997, p. 197-213.

PINHEIRO, P. S. Transição política e não-estado de direito na República. In: SACHS, I., WILHEIM, J., PINEIRO, P. S. Brasil: um século de transformações. São Paulo: Companhia das letras, 2001.

RIBEIRO, C. Z. Pedido de socorro exige resposta imediata. Fortaleza, Jornal O POVO, 5/02/2002. Opinião, p. 7 (Artigo).

SALES, C. Projetos demais, votação de menos. Fortaleza, Jornal O POVO, 28/01/ 2002. Política, p. 14 (Reportagem).

SANTOS, J. V. T. dos. A arma e a flor: formação da organização policial, consenso e violência. São Paulo, Tempo Social, v. 9, n. 1, 1997, p. 155-167.

SECCO, A. É possível sair do caos. São Paulo, VEJA, p. 74-8, 30/01/02 (Reportagem). 


\section{Resumo}

O presente artigo tem como objetivo discutir e analisar a experiência de integração vivenciada pelos policiais civis e militares a partir das ações policiais desenvolvidas nos Distritos-Modelo, criados no Ceará em 1998. Estes são vistos como modelos de integração de uma política de segurança pública que unificou o seu comando no Estado e tem buscado a integração das ações policiais em toda a estrutura de poder dos aparelhos policiais, apesar das diferenças de atribuições e interesses, das disputas e rusgas existentes entre as duas policias.

Palavras-chave: integração, parceria, unificação, polícia judiciária, polícia ostensiva, militarismo, disciplina e hierarquia. 